\title{
NOVEL PHOTOSYNTHESIS AND CHARACTERIZATION OF 4-(5,7- DICHLORO-8aH-CHROMENE-2-YL)-N, N-DIMETHYLANILINE FROM ITS CHALCONE ISOMER
}

\author{
NiROZH A. Chalabi ${ }^{*}$ and GHAZWAN F. FADHIL ${ }^{* *}$ \\ Dept. of Medicinal Chemistry, College of Pharmacy, University of Duhok, Kurdistan Region - Iraq \\ ** Dept. of Chemistry, College of Science, University of Duhok, Kurdistan Region- Iraq
}

(Received: October 5, 2020; Accepted for Publication: November 2, 2020)

\begin{abstract}
In the present study, trans-3-(2,4-dichlorophenyl)-1-(4-(dimethylamino)phenyl)prop-2-en-1-one (trans 2,4-dimethyl amino chalcone) was synthesized by Claisen-Schmidt reaction in the presence of aqueous alcoholic alkali solution by condensation of a substituted acetophenone with substituted benzaldehydes, Then, The photosynthesis of 4-(5,7-dichloro-8aH-chromen-2-yl)-N, $\mathrm{N}$-dimethylaniline (2,4-dimethylamino chromene) was accomplished from the irradiation of the( trans 2,4-dimethyl amino chalcone) with xenon light. The products were characterized by UV-Visible, FT-IR, ${ }^{1}$ HNMR, thin layer chromatography Elemental analysis(CHNO) and liquid chromatography-quadrupole-time-of-flight mass spectrometry (LC-Q-ToF-MS).
\end{abstract}

KEYWORDS: Chalcone, Chromene, FT-IR, NMR, LC/Q-TOF/MS, CHNO.

\section{INTRODUCTION}

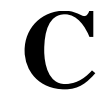
halcones ones) belong

as natural (1,3-diaryl-2-propen-1to the flavonoid class or synthetic compounds. Chemically, they consist of open-chain flavonoids in which a 3 Cs $\alpha, \beta$-unsaturated carbonyl system joins the 2 aromatic rings. They include the keto-ethylene group(-CO-
$\mathrm{CH}=\mathrm{CH})$. Chalcones have conjugated double bond and a fully delocalized $\pi$ electrons framework on both benzene rings(Yadav et al., 2012). Chalcone could be stereochemically trans (E) and cis (Z) isomers, but the $Z$ conformer is most unstable due to the steric effects of ring $A$ with carbonyl group(Rammohan, 2020).

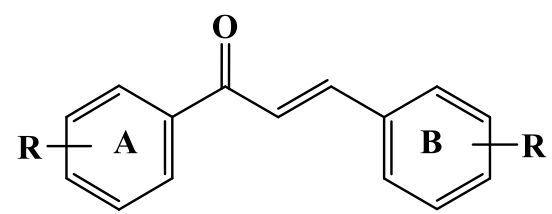

Fig. (1): Chalcone structure

Unsaturated carbonyl group in the chalcone allows it to be active biologically active(Archit, Mythili, and Sathiavelu, 2014). It has been reported that compounds with the backbone of chalcones have different biological activities. For example antimicrobial(Dekić et al., 2017), ant- inflammatory(Zhuang et al., 2017), analgesic(Asiri et al., 2015), anticancer(Tran et al., 2016), antiviral and antioxidant(Orlikova, Tasdemir, Golais, Dicato, and Diederich, 2011). Due to their interesting uses such as chemical probes, electrochromic products, Fluorescent dyes, sensors, as additives in dye-sensitized solar cells, and more specifically in the evaluation of new drug production. Fluorescent products have a lot of interest(Watanabe, Saji, and Ono, 2018)'(Zhou, Jiang, Lu, and Xing, 2016)'(Tomasch, Schwed, Weizel, and Stark, 2012)'(RJ, 2011) . Chromenes, probably, represent an important structural class of oxygen heterocycles. The chromene ring (benzopyran) system consisting of a benzene ring fused to a pyran ring(Costa, Dias, Brito, and Proença, 2016). Classification of heterocyclic pyran compounds depends on the existence of the pyran scaffold $2 \mathrm{H}$ or $4 \mathrm{H}$. So, the $2 \mathrm{H}$-pyran benzo analogue is called $2 H$-1-benzopyran (usually $2 H$-chromene) and the $4 H$-pyran benzo 
analog is called $4 H$-1-benzopyran (usually $4 H$ chromene)(Kumar et al., 2017). Of the nine ring structure carbons, eight are $\mathrm{sp}^{2}$ and one is $\mathrm{sp}^{3}$ hybridized. These are often referred to as $2 \mathrm{H}$ and $4 H$-chromes based on the position of $\mathrm{sp}^{3} \mathrm{C}$ in relation to ring oxygen. Chromene reactions with weaker nucleophiles give a replacement product at C-4, whereas strong nucleophile attacks at $\mathrm{C}-2$ carbon produce dianion of phenolic acid by cleavage of pyran ring. In case of $4 \mathrm{H}$-cromene, the $\mathrm{C}=\mathrm{C}$ bond is not in conjugation with a benzene ring like $2 \mathrm{H}$ chromene(Pratap and Ram, 2014)
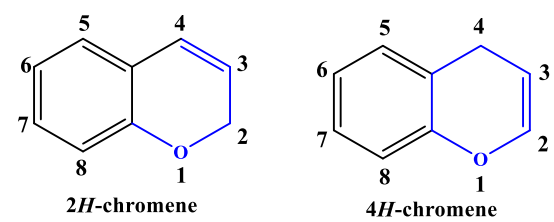

Fig. (2): General structure of $2 \mathrm{H}$-chromenes and $4 \mathrm{H}$-chromene

The aim of this study is to synthesize trans-3-
4-dichlorophenyl)-1-(4(dimethylamino)phenyl)prop-2-en-1-one (trans 2,4-dimethylamino chalcone) by Clasien Schmidt reaction, then using simple photochemical conversion by the xenon light to synthesize the 4-(5,7-dichloro-8aH-chromen-2yl)-N,N-dimethylaniline (2,4-

dimethylaminochromene). These two products will be characterized by different techniques such as, thin layer chromatography, FT-IR, ${ }^{1} \mathrm{H}$ and ${ }^{13} \mathrm{C}$ nuclear magnetic resonance, liquid chromatography/quadrupole time-of-flight mass spectrometry and elemental analysis (CHNO).

\section{EXPERIMENTAL}

\section{Materials and Methods}

All the needed chemicals and solvents were of reagent grade bought from Sigma Aldrich and Merck. The melting points have been identified and recorded using an open capillary method and are uncorrected by using the Mel-temp M206780/02 electro thermal melting point apparatus. ${ }^{1} \mathrm{H}$ and ${ }^{13} \mathrm{C}$ NMR data were recorded on BRUKER AV400-MHz NMR (Bruker Corporation, USA) spectrometer in $\mathrm{CDCl}_{3}$ and DMSO solvents. For 2,4-dimethylamino chromene, one drop of $1 \mathrm{M} \mathrm{HCl}$ was added with solvent to prevent the conversion of chromenes to chlacones during NMR measurement like the flavylium salt compounds(Gavara, Gago, Jordão, and Pina, 2014). The NMR spectra obtained were carried out in laboratories of Chemistry Department at the University of Dicle, Turkey. Chemical shift is expressed in part per million ( $\delta)$ using tetra methyl silane (TMS) as internal standard. Deuterated solvents were supplied from Merck (Darmstad, Germany). ATR-FT-IR was employed to receive infrared spectra
(Schimadzu, Japan). Chalcones and chromenes FTIR spectra were obtained in solid state. The obtained IR spectra were performed in the laboratories of Chemistry Department at Dicle University in the Diyarbakir Turkey. Elemental analysis (CHNO) was measured by Perkin Elmer EA 2400 series II (Perkin Elmer, USA). MS analysis was performed using an Agilent 6550 iFunnel high resolution Accurate-Mass Q-T-OFMS (Agilent Technologies, Santa Clara, CA, USA). Thin Layer Chromatography was made on Macherey-Nagel, 805022, pre-coated TLCsheets Polygram Sil/ $\mathrm{UV}_{254}$, the detection of spots on TLC sheet visualized with a UV lamp with $\lambda_{\max } 254 \mathrm{~nm}$. The irradiation light source for performing the chalcone to chromene reaction is 100W Auto Car HID Xenon Headlight Lamp was used as a source of irradiation. ChemDraw professional 15.0 software was used for drawing structures. MestReNova software version:6.0.25475 was used for plotting FT- NMR spectra and for chemical shifts prediction.

Preparation of trans-3-(2,4-dichlorophenyl)-1(4) (dimethylamino)phenyl)prop-2-en-1one.[2,4-dimethylamino chalcone]

A quantity $(24.9 \mathrm{mmol}, 4 \mathrm{~g})$ of 4 dimethylamino acetophenone and $(24.9 \mathrm{mmol}$, $4.3 \mathrm{~g})$ of (2,4-dichlorobenzaldehyd) were dissolved in $20 \mathrm{ml}$ of absolute ethanol and then were mixed, to this solution $5 \mathrm{ml}$ of $(10 \%)$ sodium hydroxide $\mathrm{NaOH}$ was added slowly with stirring, after $1 \mathrm{~h}$. A precipitate was formed then stirring was continued for $24 \mathrm{~h}$. The reaction mixture then was placed in a refrigerator for an overnight. The formed precipitate was filtered and washed several times with cold distilled water to remove excess base and was recrystallized from hot absolute ethanol. The purity of product was checked by melting point 
$\left(112-115{ }^{\circ} \mathrm{C}\right)$ (uncorrected) and thin layer ethyl acetate) (6:2) were used as eluent. The chromatographed $(\mathrm{TLC})\left(\mathrm{R}_{\mathrm{f}}=0.64\right)$ (toluene: yield of yellow precipitate was $(80 \%)$.

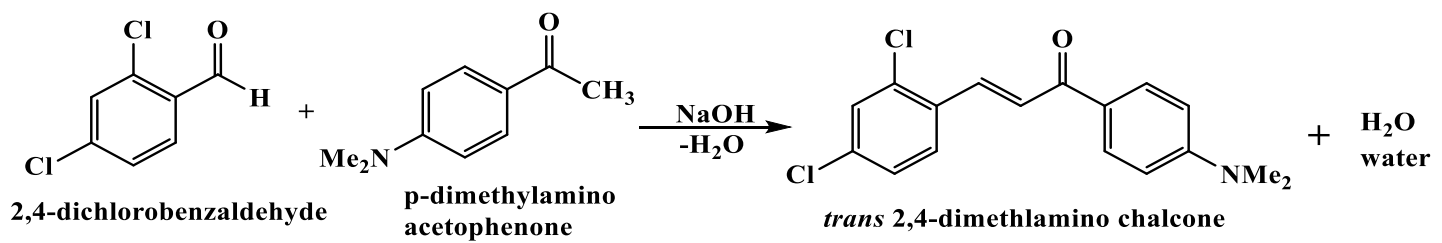

Scheme (1): Reaction equation for preparation of trans-3-(2,4-dichlorophenyl)-1-(4 (dimethylamino)phenyl) prop-2-en-1-one

Preparation of 4-(5,7-dichloro-8aH-chromen2-yl)-N,N-dimethylaniline. [2,4dimethylamino chromene]

A quantity $(3.125 \mathrm{mmol}, \quad 1 \mathrm{~g})$ of $2,4-$ dimethylamino chalcone was dissolved in a mixture of $(80 \mathrm{ml}$ of cyclohexane and $20 \mathrm{ml}$ of chloroform) and was stirred in an ice bath. Then the solution was irradiated with the xenon light for $1 \mathrm{~h}$, during time, color of the solution was changed from yellow to purplish-black solution.
The purplish-black solution starts to precipitate because of the low solubility of the product $(2,4-$ dimethyl amino chromene) in cyclohexane. Under the xenon light the precipitate was filtered directly. The purity of the precipitate was identified by TLC $\left(R_{f}=0\right)$ using toluene and ethyl acetate as eluents (6:2) with one drop of $1 \mathrm{M} \mathrm{HCl}$. The yield of purplish-black precipitate was $(80 \%)$ and the melting point was $\left(115-117^{\circ}\right.$ C).<smiles>CN(C)c1ccc(C(=O)/C=C\c2ccc(Cl)cc2Cl)cc1</smiles><smiles>[Y][13CH3]</smiles><smiles>C=CC1=C(c2ccc(N(C)C)cc2)C(=C)Oc2cc(Cl)cc(Cl)c21</smiles>

2,4-dimethylamino chromene

Scheme (2): Reaction equation for preparation of 4-(5,7-dichloro-8aH-chromen-2-yl)-N,N-dimethylaniline

\section{RESULTS AND DISCUSSION}

In the reaction of 2,4-dimethylamino chromene synthesis, the newly synthesized trans 2,4-dimethylamino chalcone was irradiated in chloroform for a limited period of time. The irradiated trans 2,4-dimethylamino chalcone expected to undergo trans-cis isomerization to give the cis 2,4-dimethylamino chalcone isomer. Further isomerizes of cis 2,4-dimethylamino chalcone isomer gives the corresponding 2,4dimethylamino chromene. The suggested reaction route is given below. 


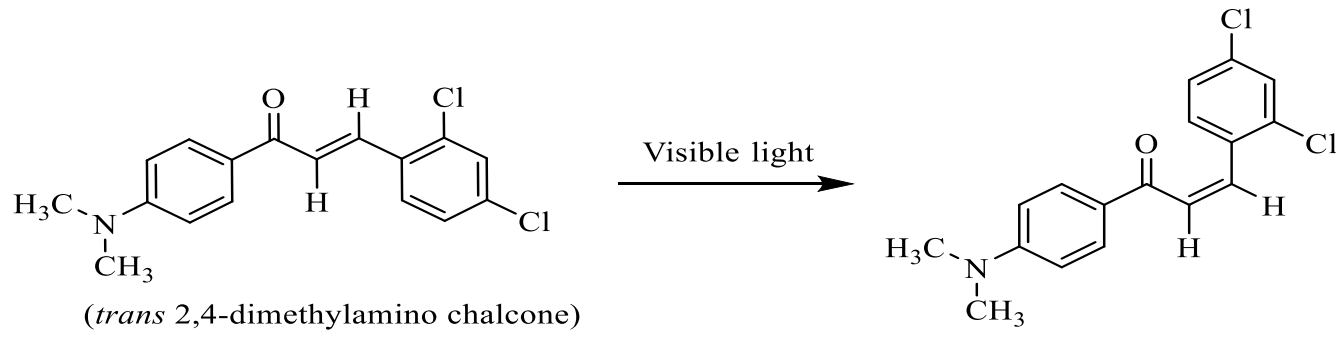

(cis 2,4-dimethylamino chalcone)

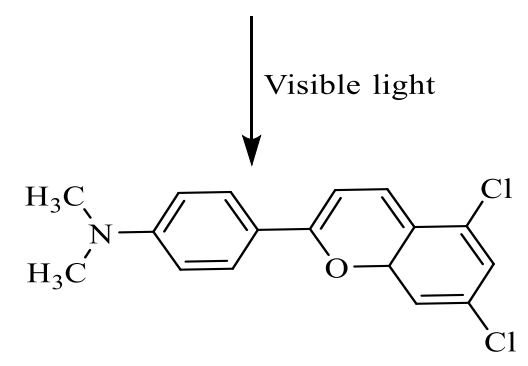

(2,4-dimethylamino chromene)

Scheme (3): The synthetic route of 2,4-dimethylamino chromene form trans 2,4-dimethylamino chalcone

\section{FT-IR Spectra Elucidation}

The experimental FT-IR spectra of trans 2,4dimethylamino chalcone and 2,4-dimethylamino chromene are illustrated in Figure (3) and (4).

The $(\mathrm{C}=\mathrm{C})$ stretching vibration for alkene usually occurs in the region $1600-1660 \mathrm{~cm}^{-1}$ and for aromatic ring is $1475-1620 \mathrm{~cm}^{-1}$ (Pavia, D.L., Lampman, G.M., Kriz, G.S. and Vyvyan, 2014). The $(\mathrm{C}=\mathrm{O})$ carbonyl stretching frequency is the most widely studied by infrared spectroscopy (Sudha, Sundaraganesan, Vanchinathan, Muthu, and Meenakshisundaram, 2012) The carbonyl group of ketones (Ar-CO$\mathrm{Ar})$ conjugated with two aromatic rings appear in region 1600-1670 $\mathrm{cm}^{-1}$. The stretching bands of $(\mathrm{C}=\mathrm{C})$ of vinyl and $(\mathrm{C}=\mathrm{O})$ of trans 2,4dimethylamino chlalcone observed at $1606 \mathrm{~cm}^{-1}$ and $1648 \mathrm{~cm}^{-1}$ respectively. But in 2,4dimethylamino chromene no $\mathrm{C}=\mathrm{O}$ vibrating bands were observed, this is an important indication that trans 2,4-dimethylamino chalcone is entirely transformed into 2,4dimethlyamino chromene. Also, for aromatic ring the $(\mathrm{C}=\mathrm{C})$ stretching is appeared at 1580 $\mathrm{cm}^{-1}$ for trans 2,4-dimethylamino chalcone and $1511 \mathrm{~cm}^{-1}$ for 2,4-dimethylamino chromene respectively.

Absorption frequency in aromatic amines is higher than aliphatic amines because resonance elevates double bond character between the ring and the linked nitrogen $\left(-\mathrm{N}\left(\mathrm{CH}_{3}\right)_{2}\right)$ atom (Sudha et al., 2012).

In this study, the C-N stretching band observed in overlap with other groups at
$1231 \mathrm{~cm}^{-1}$ for trans 2,4-dimethylamino chalcone and $1227 \mathrm{~cm}^{-1}$ belongs to 2,4-dimethylamino chromene.

The stretching vibration of $\mathrm{sp}^{2}(\mathrm{C}-\mathrm{H})$ of aromatic compounds commonly shows multiple weak bands in the region 3000 and $3150 \mathrm{~cm}^{-1}$. The experimental vibrational wavenumbers of $\mathrm{sp}^{2}(\mathrm{C}-\mathrm{H})$ of trans 2,4-dimethylamino chalcone and 2,4-dimethylamino chromene were observed at $3065 \mathrm{~cm}^{-1}$ and $3064 \mathrm{~cm}^{-1}$ respectively. Whereas $\mathrm{sp}^{2}(\mathrm{C}-\mathrm{H})$ out of plane (oop) bending and in plane (ip) ring (Ar) bending vibration occurs in the range 1000-650 $\mathrm{cm}^{-1}$ and 1000-1300 $\mathrm{cm}^{-1}$ respectively (Mahadevan, Periandy, and Ramalingam, 2011). For trans 2,4dimethylamino chalcone $(\mathrm{C}-\mathrm{H})$ out of plane (oop)bending and in plane(ip) vibration appears in the $813 \mathrm{~cm}^{-1}$ and $1337 \mathrm{~cm}^{-1}$ respectively and $828 \mathrm{~cm}^{-1}, 1185 \mathrm{~cm}^{-1}$ for 2,4-dimethylamino chromene. Stretching vibration of $\mathrm{sp}^{3}(\mathrm{C}-\mathrm{H})$ occur in the region of $2850-3000 \mathrm{~cm}^{-1}$ (Robert, 2005). The symmetric bending vibration $\left(\mathrm{CH}_{3}\right)$ appears around $1375 \mathrm{~cm}^{-1}$, and the asymmetric bending vibration $\left(\mathrm{CH}_{3}\right)$ is about $1450 \mathrm{~cm}^{-1}$. for the synthesized chalcone The stretching $\mathrm{sp}^{3}(\mathrm{C}$ $\mathrm{H})$, C-H bending symmetrical $\left(\mathrm{CH}_{3}\right)$ and asymmetric bending vibration $\left(\mathrm{CH}_{3}\right)$ observed in the $2990 \mathrm{~cm}^{-1}, 1369 \mathrm{~cm}^{-1}$ and $1444 \mathrm{~cm}^{-1}$, respectively. However, for 2,4-dimethylamino chromene stretching $\mathrm{sp}^{3}(\mathrm{C}-\mathrm{H})$ appeared in 2918 $\mathrm{cm}^{-1}$, whereas $\mathrm{C}-\mathrm{H}$ bending symmetrical $\left(\mathrm{CH}_{3}\right)$ and asymmetric bending vibration $\left(\mathrm{CH}_{3}\right)$ were 
appeared in $1372 \mathrm{~cm}^{-1}$ and $1468 \mathrm{~cm}^{-1}$ respectively.

The experimental vibrational wavenumbers of $(=\mathrm{C}-\mathrm{H})$ of the trans 2,4-dimethylamino chalcone and 2,4-dimethylamino chromene were observed at $\quad 3065 \mathrm{~cm}^{-1}$ and $3064 \mathrm{~cm}^{-1}$ respectively. Whereas $(=\mathrm{C}-\mathrm{H})$ out of plane (oop) bending and in plane(ip) ( $\mathrm{C}-\mathrm{H}$ ring(Ar) bending vibration) occurs in the range $1000-650 \mathrm{~cm}^{-1}$ and $1000-1300 \mathrm{~cm}^{-1}$ respectively (Mahadevan et al., 2011). For the trans 2,4-dimethylamino chalcone, (=C-H) out of plane (oop) bending and in plane(ip) bending vibrations were appeared in the $813 \mathrm{~cm}^{-1}$ and $1337 \mathrm{~cm}^{-1}$ respectively, and at $828 \mathrm{~cm}^{-1}, 1185 \mathrm{~cm}^{-1}$ which belongs to $2,4-$ dimethylamino chromene. The stretching vibration of $(-\mathrm{C}-\mathrm{H})$ occurs in the region of 2850-3000 $\mathrm{cm}^{-1}$ (Robert, 2005). The symmetric bending vibration $\left(\mathrm{CH}_{3}\right)$ appears around 1375 $\mathrm{cm}^{-1}$, the asymmetric bending vibration $\left(\mathrm{CH}_{3}\right)$ is about $1450 \mathrm{~cm}^{-1}$. for the synthesized chalcone the stretching $\mathrm{sp}^{3}(\mathrm{C}-\mathrm{H}), \quad \mathrm{C}-\mathrm{H} \quad$ bending symmetrical $\left(\mathrm{CH}_{3}\right)$ and asymmetric bending vibration $\left(\mathrm{CH}_{3}\right)$ observed in the $2990 \mathrm{~cm}^{-1}, 1369$ $\mathrm{cm}^{-1}$ and $1444 \mathrm{~cm}^{-1}$ respectively. However, for 2,4-dimethylamino chromene stretching $\mathrm{sp}^{3}(\mathrm{C}$ $\mathrm{H})$ appeared in $2918 \mathrm{~cm}^{-1}$, whereas $\mathrm{C}-\mathrm{H}$ bending symmetrical $\left(\mathrm{CH}_{3}\right)$ and asymmetric bending vibration $\left(\mathrm{CH}_{3}\right)$ were $1372 \mathrm{~cm}^{-1}$ and $1468 \mathrm{~cm}^{-1}$ respectively.

Aryl $(\mathrm{C}-\mathrm{Cl})$ stretching vibration absorbed in the region 1035-1100 $\mathrm{cm}^{-1}$, while for aliphatic $\mathrm{C}-\mathrm{Cl}$ is absorbed at $550-850 \mathrm{~cm}^{-1}$ (Pavia, D.L., Lampman, G.M., Kriz, G.S. and Vyvyan, 2014). For the studied compounds, the bands of C-Cl stretching were observed experimentally at 1099 $\mathrm{cm}^{-1}$ for trans 2, 4-dimethylamino chalcone and at $591 \mathrm{~cm}^{-1}$ for 2, 4-dimethylamino chromene. 


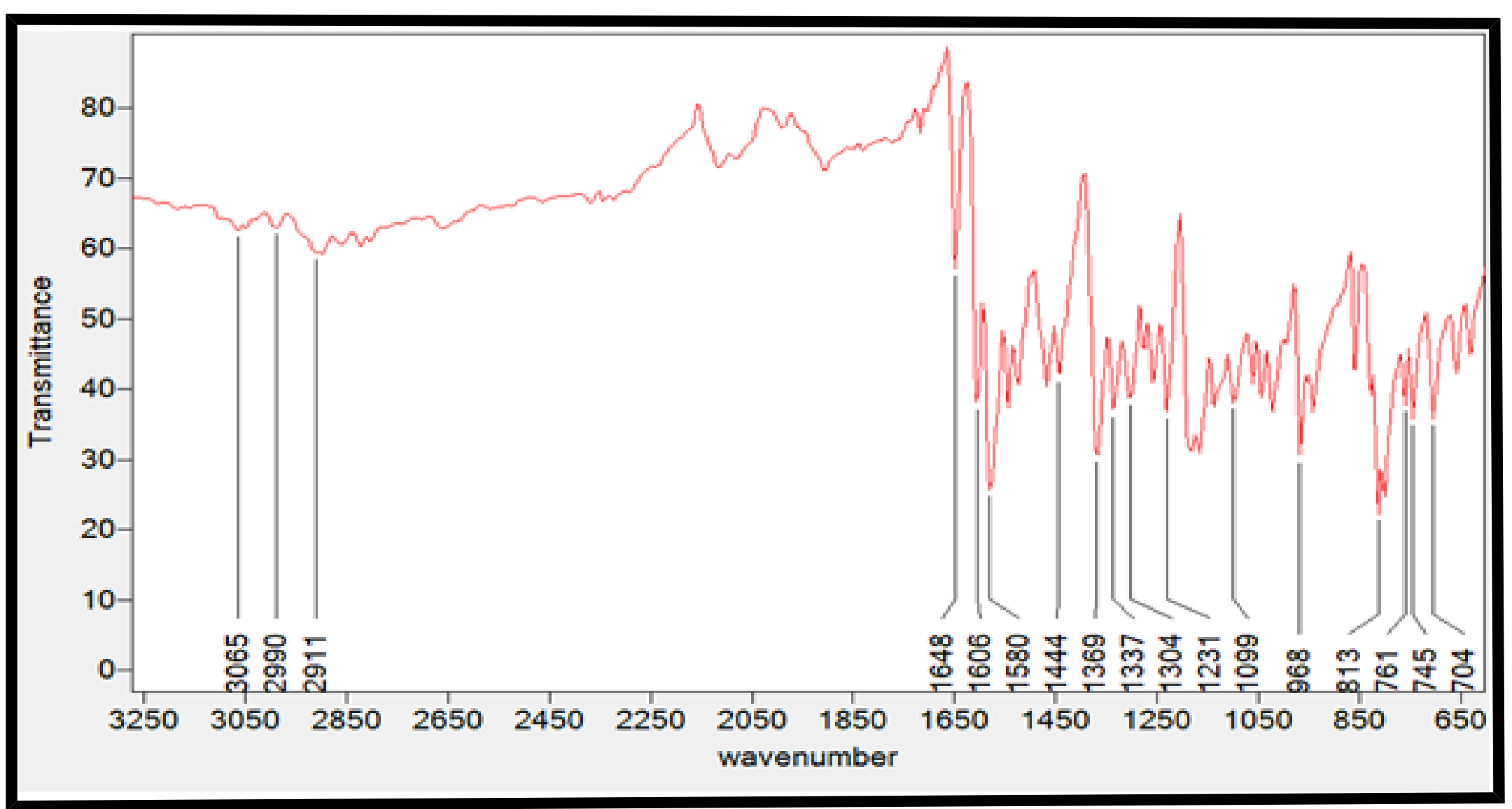

Fig. (3):.ATR- FT-IR spectrum of trans 2,4-dimethylamino chalcone 


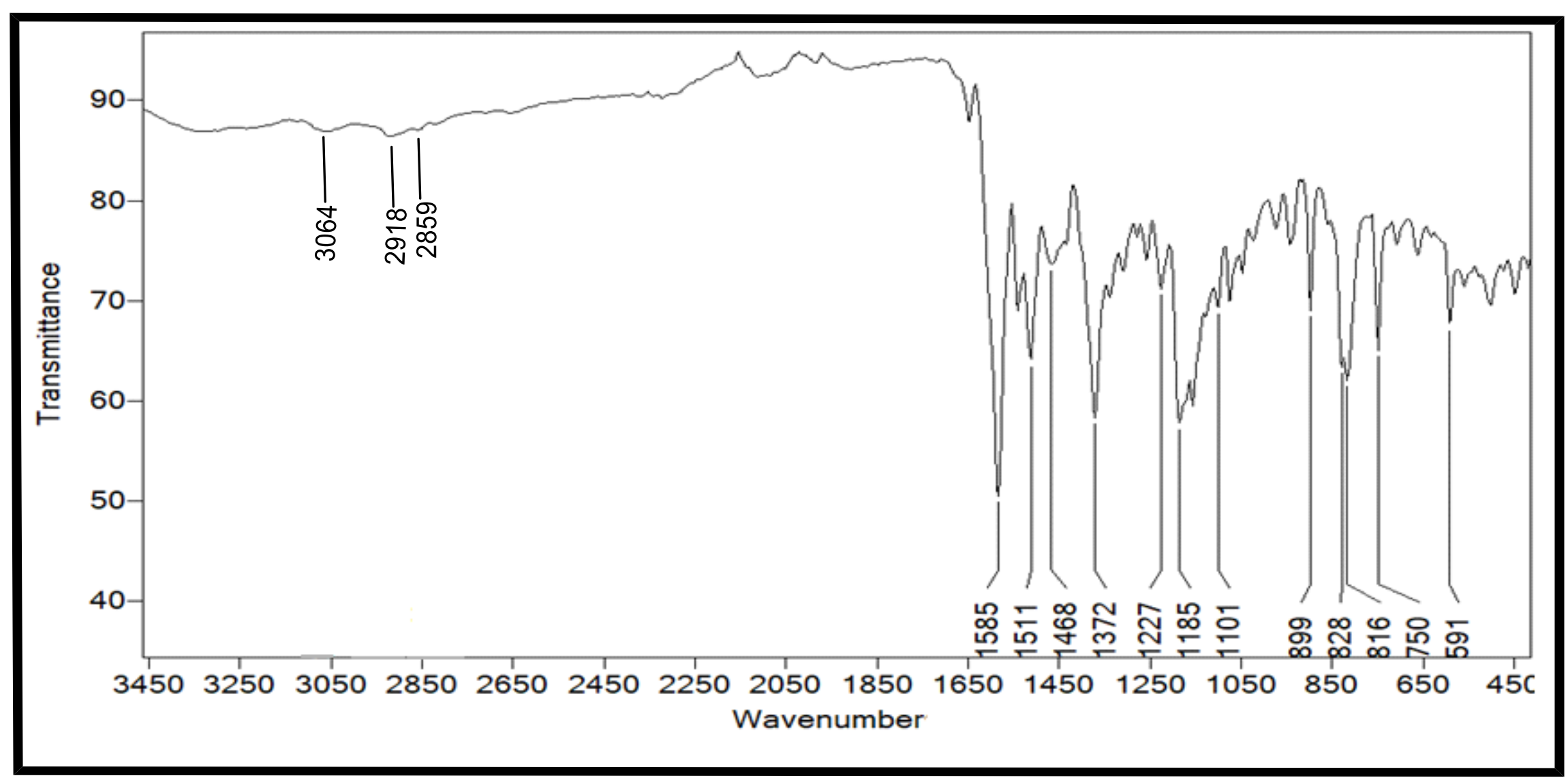

Fig. (4): ATR-FT-IR spectrum of 2,4-dimethylamino chromene 


\section{NMR Analysis}

The ${ }^{1} \mathrm{H}-\mathrm{NMR}$ and ${ }^{13} \mathrm{C}-\mathrm{NMR}$ spectra of trans 2,4dimethylamino chalcone and 2,4-dimethlamino chromene are illustrated in Figures (6), (7) and (8) respectively. Table 1 and 2 show the ${ }^{1} \mathrm{H}-\mathrm{NMR}$ chemical shifts, $J$ coupling constants and integrations of trans 2,4-dimethylamino chalcone and 2,4dimethylamino chromene, respectively.

The H5 $(\alpha)$ and H6( $\beta)$ vinyl group protons belong to the AB (Zhou et al., 2016) system in which the four signals are classified as doublet of doublet. The signals of each splitted doublet with not equal intensity i.e. not like the first order splitting. The trans-vinyl protons have coupling constant that is noticeably greater than the coupling constant of the cis-vinylic protons. In trans 2,4-dimethylamino chalcone the chemical shift of $\alpha$ hydrogen (H5) is lower than for $\beta$ hydrogen (H6) (Table, 1) due to high electron density around $\mathrm{H} 5$ as a result of the resonance interaction of the vinyl double bond with the carbonyl group. The coupling constant $(J)$ for these protons is $16.084 \mathrm{~Hz}$ agrees with the trans coupling constant of protons. Chemical shifts and coupling constants of $\mathrm{H} 5$ and $\mathrm{H} 6$ of 2,4dimethylamino chromene are given in Table (2). The splitting pattern of these protons gives two doublets, however, the peak ratio of each doublet is not like that in $\mathrm{H} 5$ and $\mathrm{H} 6$ of trans chalcone, and the coupling constants for 2,4-dimethylamino chromene is $8.5 \mathrm{~Hz}$. This is due to non-trans geometry and confirms the cis relationship between the $\mathrm{H} 5$ and $\mathrm{H} 6$ protons in the synthesized chromene. This is one of the significant evidence of the chromene synthesis from trans chlacone. The chemical shifts of C8 and C9 ${ }^{13} \mathrm{C}-\mathrm{NMR}$ of trans 2,4-dimethylamino chalcone behave in a similar manner as $\mathrm{H} 5$ and $\mathrm{H} 6$ due to the same resonance effect discussed above.

The protons of dimethyl amino group ring belong to AA'BB' (Bruice, 2004) splitting pattern which is a typical pattern of splitting of para di-substituted benzene ring. The observed ${ }^{1} \mathrm{H}-\mathrm{NMR}$ spectrum for $\mathrm{H} 1, \mathrm{H} 2, \mathrm{H} 3$ and $\mathrm{H} 4$ of the aniline ring of trans 2,4- dimethylamino chalcone and 2,4-dimethylamino chromene are shown in Figures (6) and (7), respectively. The pattern of splitting gave two pairs of signals one pair for $\mathrm{H} 1$ and $\mathrm{H} 2$ which is similar image with the pair of signals of $\mathrm{H} 3$ and $\mathrm{H} 4$. The electron-donating by resonance effect of the dimethyl amino group increases the electron density on ortho and para position while has no effect on meta position. According to that, the chemical shifts of H1$\mathrm{H} 2$ and $\mathrm{C} 2-\mathrm{C} 3$ are lower (up field shifted) than that of $\mathrm{H} 3-\mathrm{H} 4$ and C4-C5. The chemical shift of ${ }^{13} \mathrm{C}-\mathrm{NMR}$ of carbonyl group (C7) appears at $187.16 \mathrm{ppm}$ in the trans 2,4-dimethlamino chalcone is higher chemical shift value (downfield) in the ${ }^{13} \mathrm{C}$ spectrum is due to the anisotropic effect of the carbonyl group.

The tree diagram for the splitting pattern of the $\mathrm{H} 7, \mathrm{H} 8$ and $\mathrm{H} 9$ of dichlorobenzene ring for trans 2,4dimethylamino chalcone shown in Figure (5). Also, the corresponding chemical shifts and coupling constants are given in Table (1). The trend of these protons chemical shift is $\mathrm{H} 9$ most downfield then $\mathrm{H} 7$ which lies between the two chlorines, after that the least deshielded is $\mathrm{H} 8$ which gives doublet of doublet signal at $7.28 \mathrm{ppm}$ embraces the residual proton signal of $\mathrm{CDCl}_{3}$, The largest coupling constant is between $\mathrm{H} 8$ and $\mathrm{H} 9$, and it is $8.51 \mathrm{~Hz}$; however, this signal was splitted further by the $\mathrm{H} 7$ with $\mathrm{J} 87$ equal to $2.2 \mathrm{~Hz}$. The chemical shift of $\mathrm{H} 7$ is $7.45 \mathrm{ppm}$ which appears as doublet signal due to coupling with $\mathrm{H} 8$ only and the $\mathrm{J} 78$ equal to 2.13 . The $\mathrm{H} 9$ chemical shift at 7.68 is also doublet due to coupling to $\mathrm{H} 8$ only with $\mathrm{J} 98$ equal to $8.5 \mathrm{~Hz}$. The ${ }^{1} \mathrm{H}$ NMR of 2,4didmethylamino chromene is shown in Figure (7). Most of the signals of the chalcone and chromene in this spectrum are overlapped. Two doublets could be recognized belong to $\mathrm{H} 3$ and $\mathrm{H} 4$ at 7.22 and 7.34 ppm with $\mathrm{J} 34$ equal to $8.1 \mathrm{~Hz}$. The doublet signal at 7.81 ppm assigned to $\mathrm{H} 2$ ' and $\mathrm{H}^{\prime}$ of the disubstituted benzene ring of the chromene. In 2,4dimethylamino chromene, H9 is the most up-field due to cyclization reaction and formation of pyrane ring. 

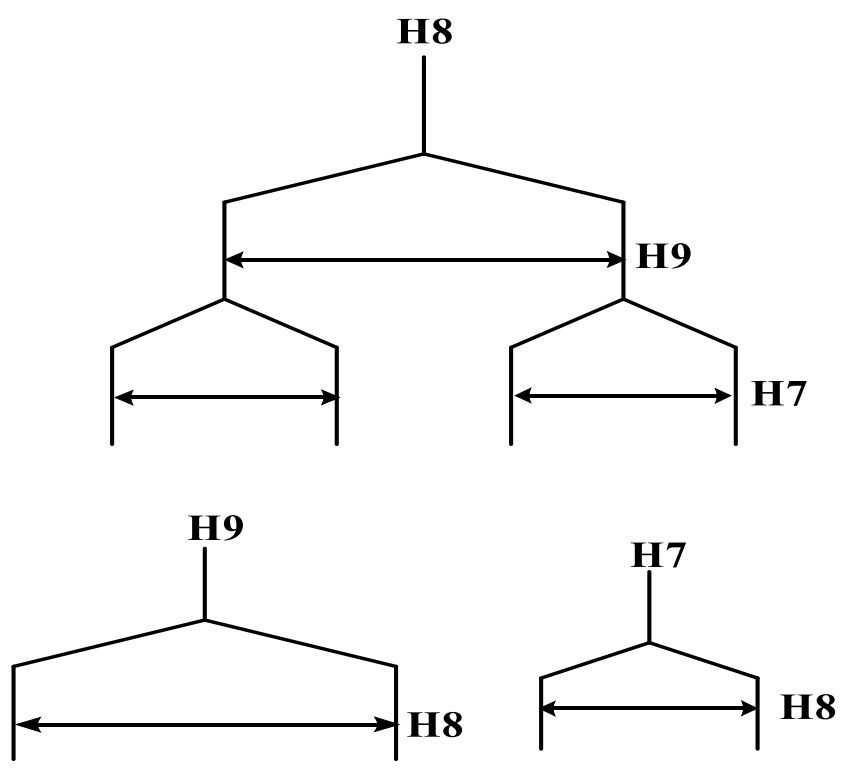

Fig. (5): Tree diagram of the splitting pattern of $\mathrm{H} 7, \mathrm{H} 8$ and $\mathrm{H} 9$ protons in trans 2,4-dimethylamino chalcone

The chemical shift of C4 and C5 is (128.44 ppm) for trans 2,4-dimethylamino chalcone are down filed compared to the chemical shift of the $\mathrm{C} 2$ and $\mathrm{C} 3$ at (110.84) as shown in Table (3). The C4 and C5 are at ortho positions with respect to the carbonyl group, and hence they are under the influence of the electron withdrawing effect of the carbonyl group.

The resonance interactions of the chlorine and the $\pi$-system of the dichlorophenyl ring in trans 2,4dimethylamino chalcone generates three negative charges at carbons $\mathrm{C} 12, \mathrm{C} 14$ and $\mathrm{C} 10$ scheme (4) structures (II and III). The chemical shift of the C14 is the most up field of the three chemical shifts and the chemical shift of $\mathrm{C} 12$ is also up field compared to chemical shift of $\mathrm{C} 10$ as shown in Table (3). Both positions $\mathrm{C} 12$ and $\mathrm{C} 14$ accommodate negative charges due to the resonance interactions, hence the up field may be justified. The C12 is between two chlorines, so it may suffer from some electron withdrawing and consequently its chemical shift is slightly down field to the chemical shift of $\mathrm{C} 14$. However, the chemical shift of $\mathrm{C} 10$ is the most down field compared to the chemical shifts of C12, C14.<smiles>CN(C)c1ccc(C(=O)/C=C/c2ccc(Cl)cc2Cl)cc1</smiles>

(I)<smiles>CCCCCCCCCC=CC=CC(=O)c1ccc(N(C)C)cc1</smiles><smiles>CN(C)c1ccc(C(=O)/C=C/c2ccccc2Cl)cc1</smiles><smiles>CN(C)c1ccc(C(=O)/C=C/C23C=CC(Cl)C(=O)C2C=CC3Cl)cc1</smiles>

Scheme (4): Resonance structures of trans 2,4dimethylamino chalcone are generated by chlorine at C13. Similar resonance structure could be generated from chlorine at $\mathrm{C} 11$. 
Table (1): The chemical shift, J coupling constant and integration of trans 2,4-dimethylamino chalcone by ${ }^{1} \mathrm{H}-\mathrm{NMR}$

\begin{tabular}{|c|c|c|c|}
\hline Proton type & Chemical shift (ppm) & $\begin{array}{c}\text { Coupling constant }(J) \\
(\mathrm{Hz})\end{array}$ & Integration \\
\hline $\mathrm{H} 1$ and $\mathrm{H} 2$ & 6.70 & 9.11 & 2 \\
\hline $\mathrm{H} 3$ and $\mathrm{H} 4$ & 7.99 & 9.12 & 2 \\
\hline H5 & 7.53 & 15.64 & 1 \\
\hline $\mathrm{H} 6$ & 8.07 & 15.64 & 1 \\
\hline $\mathrm{H} 7$ & 7.45 & 2.1 & 1 \\
\hline $\mathrm{H} 8$ & 7.28 & 7.61 & 1 \\
\hline $\mathrm{H} 9$ & 7.68 & 8.48 & 1 \\
\hline$-\mathrm{N}\left(\mathrm{CH}_{3}\right)_{2}$ & 3.09 & - & 6 \\
\hline
\end{tabular}

Table (2): The chemical shift, J coupling constant and integration of 2,4-dimethylamino chromene by ${ }^{1} \mathrm{H}-\mathrm{NMR}$

\begin{tabular}{cccc}
\hline Proton type & Chemical shift $(\mathbf{p p m})$ & $\begin{array}{c}\text { Coupling constant }(\mathbf{J}) \\
(\mathbf{H z})\end{array}$ & Integration \\
\hline $\mathbf{H}$ 1 and H2 & 7.28 & 8.60 & 2 \\
\hline $\mathbf{H}$ 3 and H4 & 7.81 & 8.61 & 2 \\
\hline $\mathbf{H} 5$ & 7.22 & 8.5 & 1 \\
\hline $\mathbf{H} 6$ & 7.34 & 8.5 & 1 \\
\hline $\mathbf{H} 7$ & 7.16 & - & 1 \\
\hline $\mathbf{H} 8$ & 7.30 & 3.58 & 1 \\
\hline $\mathbf{H} 9$ & 6.09 & 29.74 & 6 \\
\hline$-\mathrm{N}\left(\mathrm{CH}_{3}\right)_{2}$ & 2.84 & - & \\
\hline
\end{tabular}

Table (3): The chemical shift of trans 2,4-dimethylamino chalcone by ${ }^{13} \mathrm{C}-\mathrm{NMR}$

\begin{tabular}{cc}
\hline Carbon type & Chemical shift (ppm) \\
\hline $\mathbf{C 1}$ & 153.55 \\
\hline $\mathbf{C}$ and $\mathbf{C 3}$ & 110.84 \\
\hline $\mathbf{C}$ and $\mathbf{C 5}$ & 128.44 \\
\hline $\mathbf{C 6}$ & 125.33 \\
\hline $\mathbf{C 7}$ & 187.16 \\
\hline $\mathbf{C 8}$ & 125.52 \\
\hline $\mathbf{C 9}$ & 137.01 \\
\hline $\mathbf{C 1 0}$ & 132.51 \\
\hline $\mathbf{C 1 1}$ & 135.72 \\
\hline $\mathbf{C 1 2}$ & 130.98 \\
\hline $\mathbf{C 1 3}$ & 135.75 \\
\hline $\mathbf{C 1 4}$ & 127.42 \\
\hline $\mathbf{C 1 5}$ & 129.97 \\
\hline$-\mathbf{N}\left(\mathbf{C H}_{3}\right)_{2}$ & 39.61 \\
\hline &
\end{tabular}




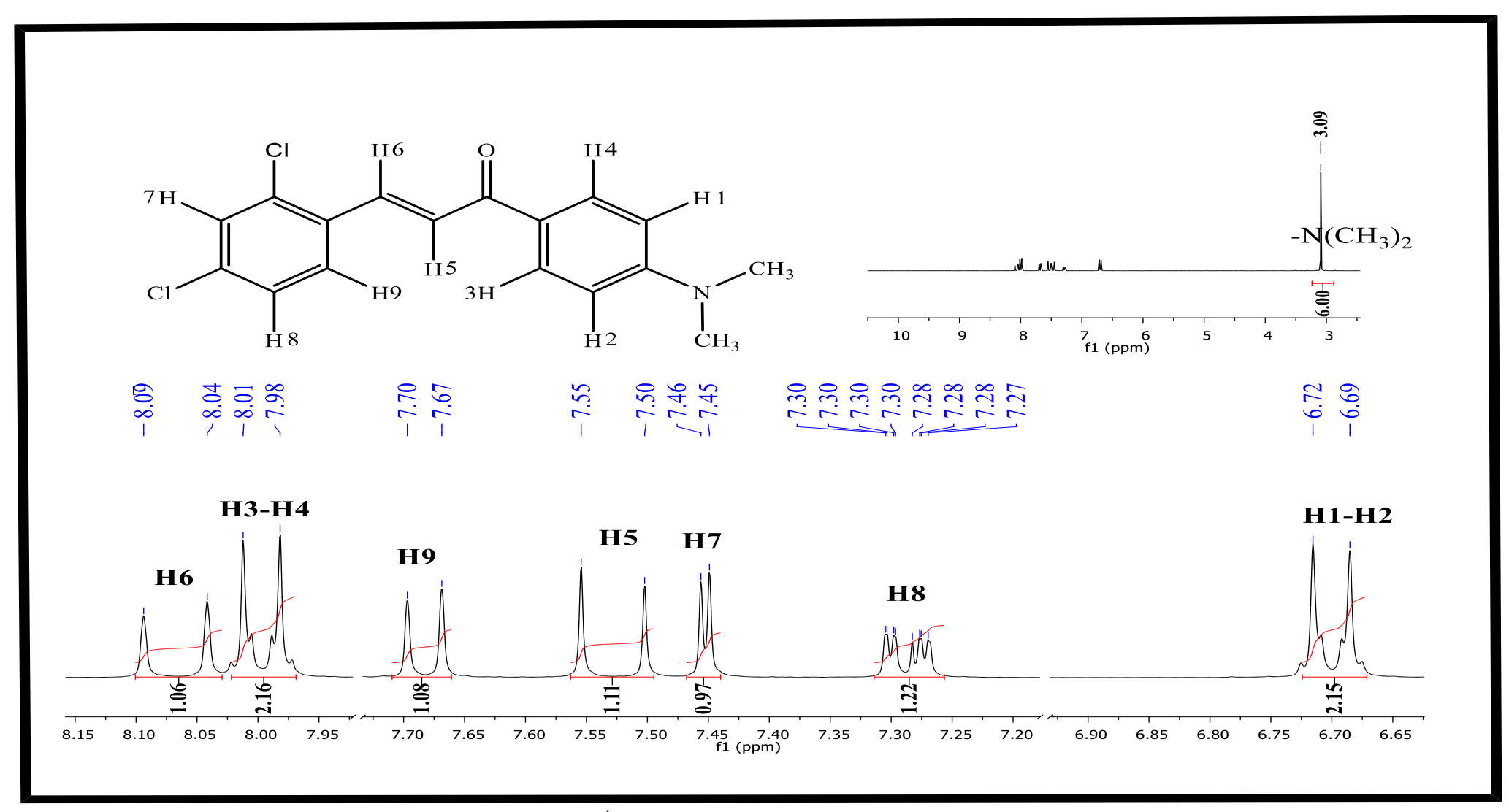

Fig. (6): ${ }^{1} \mathrm{H}-\mathrm{NMR}$ spectrum of trans 2,4-dimethylamino chalcone in $\mathrm{CDCl}_{3}$ 


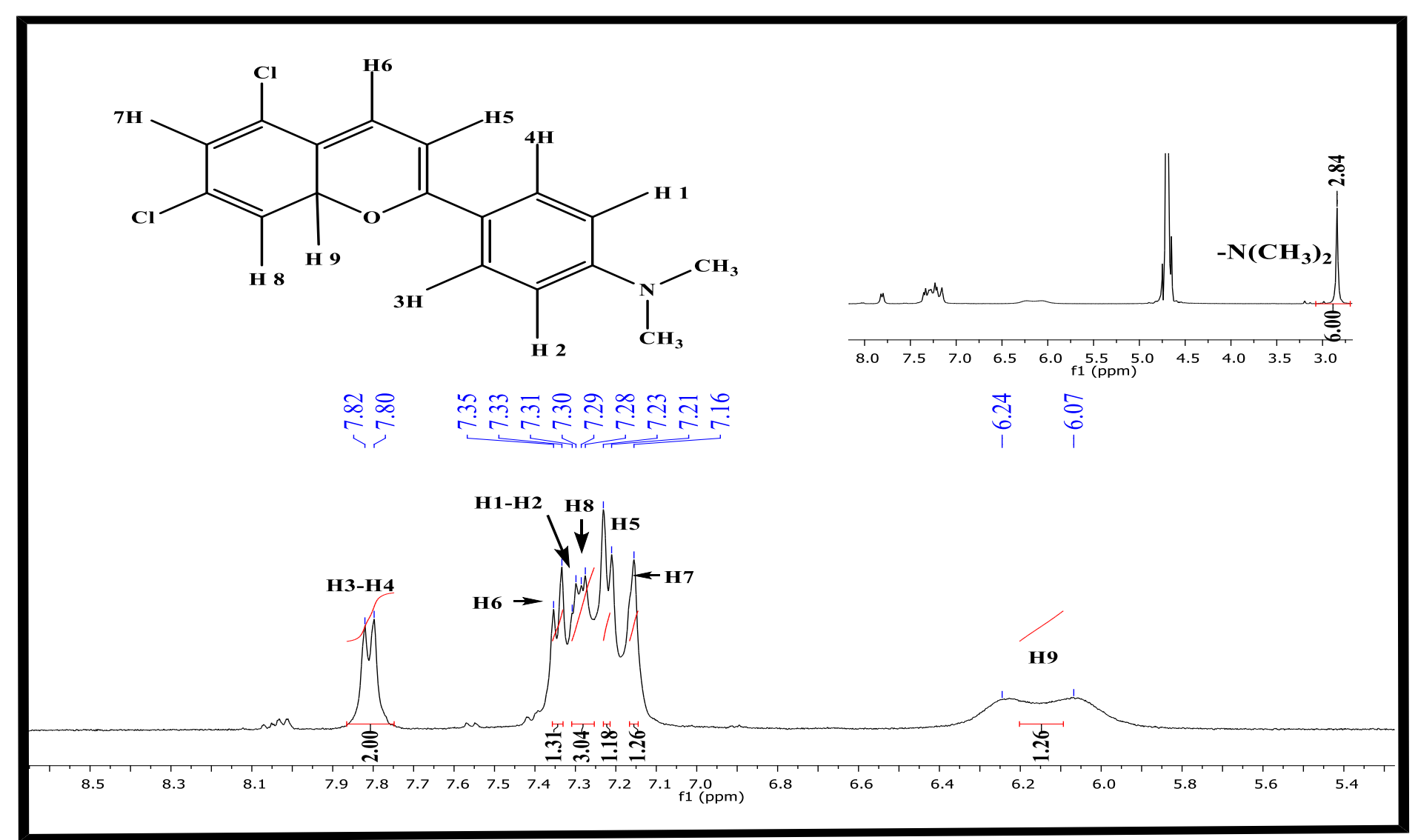

Fig. (7): ${ }^{1} \mathrm{H}-\mathrm{NMR}$ spectrum of 2,4-dimethylamino chalcone in DMSO 


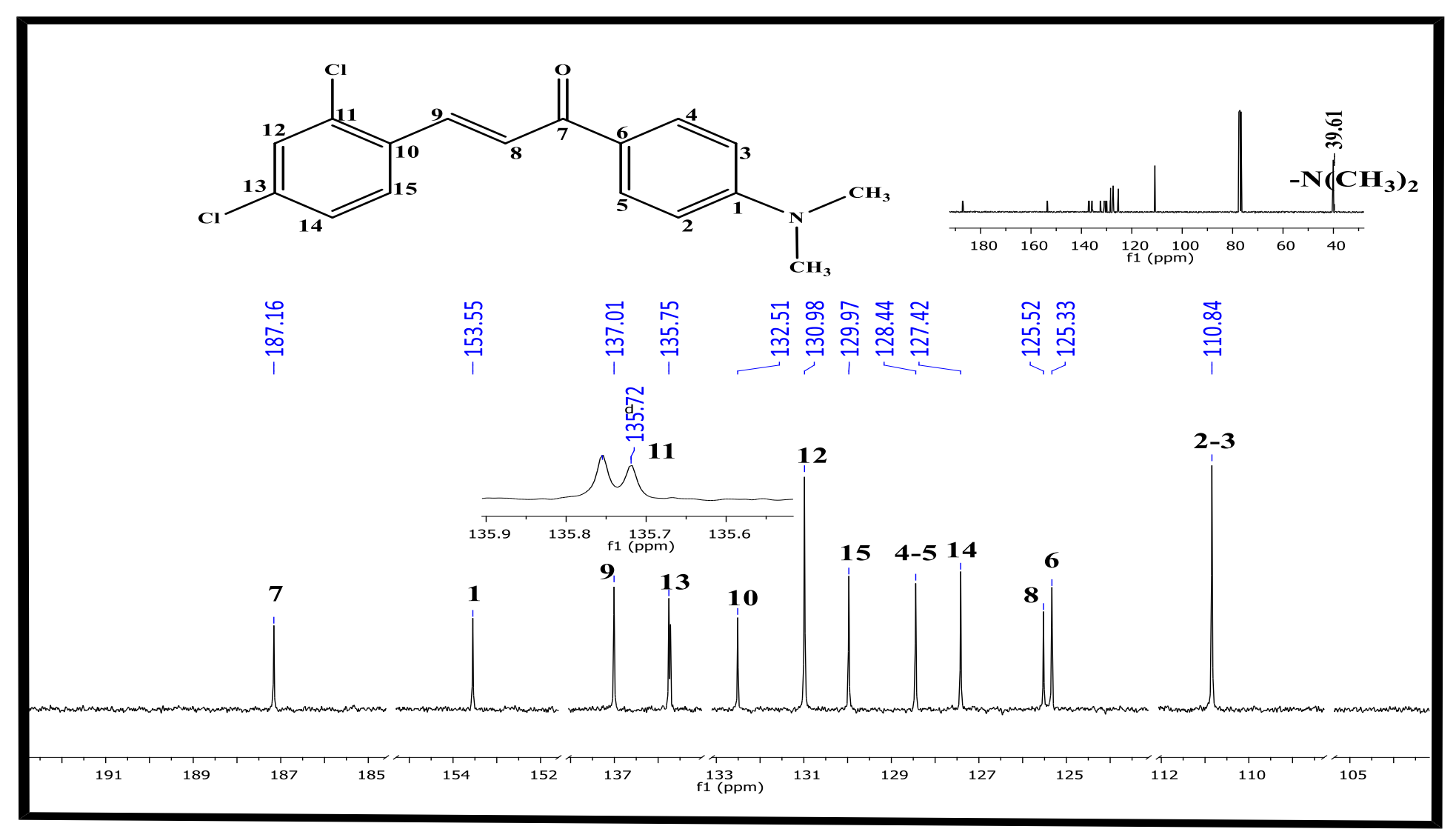

Fig. (8): ${ }^{13} \mathrm{C}-\mathrm{NMR}$ spectrum of trans 2,4-dimethylamino chalcone in $\mathrm{CDCl}_{3}$ 
Liquid Chromatography/Quadrupole Time-OfFlight/ Mass Spectrometry (LC/Q-TOF/MS)

The molecular ion of 2,4-dimethylamino chromene was determined by LC/Q-TOF-MS which is equal to $[\mathrm{M}+1 \mathrm{H}]^{+}(320.0522)$ at the retention time $7.396 \mathrm{~min}$, the calculated exact mass of 2,4dimethylamino chromene is 320.0531 .

\section{Elemental Analysis (CHNO)}

The experimental and calculated elemental analysis (CHNO) results of trans 2,4-dimethylamino chalcone and 2,4-dimethylamino chromene are shown in Table

Table (4): Calculated and found CHNO analysis of trans 2,4-dimethylamino chalcone and 2,4-dimethylamino chromene

\begin{tabular}{lcccccccc}
\hline \multicolumn{1}{c}{ Calculated } \\
\hline & C & H & N & O & C & H & N & O \\
\hline & & & & & & & & \\
\hline $\begin{array}{l}\text { 2,4-dimethylamino } \\
\text { chalcone }\end{array}$ & 63.77 & 4.72 & 4.37 & 5.00 & 63.76 & 4.71 & 4.35 & 4.98 \\
\hline $\begin{array}{l}\text { 2,4-dimethylamino } \\
\text { chromene }\end{array}$ & 63.77 & 4.72 & 4.37 & 5.00 & 63.70 & 4.79 & 4.33 & 5.04 \\
\hline
\end{tabular}

\section{CONCLUSION}

The irradiation of trans 2,4-dimethylamino chalcone with xenon light provided a simple and easy method to synthesize 2,4-dimethylamino chromene from simply synthesized trans 2,4dimethylamino chalcone via the well-known method of Claisen-Schmidt. ${ }^{1} \mathrm{H}$ NMR of chalcone and chromene shows all the prominent peaks as in the chemical structure. Chalcone molecules can be considered as photo switches since the synthesized chromene can go back to chalcone in dark or heat and by light to chromene again.

\section{ACKNOWLEDGMENT}

N.A. Chalabi is grateful to the Department of Medicinal Chemistry, College of Pharmacy, University of Duhok for the MSc studentship.

\section{REFERENCES}

Archit, R., Mythili, S., \& Sathiavelu, A. (2014). Synthesis of some new chalcone derivatives and evaluation of their Anticancer activity Page. Int. J. Drug Dev. \& Res., 6(1), 231-238.

Asiri, a. M., Karabacak, M., Sakthivel, S., Al-youbi, A., Muthu, S., Hamed, S. a., ... Alaganesan, T. (2015). Synthesis, molecular structure, spectral investigation on (E)-1-(4bromophenyl)-3-(4-

(dimethylamino)phenyl)prop-2-en-1-one.
Journal of Molecular Structure. https://doi.org/10.1016/j.molstruc.2015.08.047 Bruice, P. Y. Organic Chemistry ( $4^{\text {th }}$ Ed.). In: (University of California, Santa Barbara) published by Prentice Hall in 2004.

Costa, M., Dias, T. A., Brito, A., \& Proença, F. (2016). Biological importance of structurally diversified chromenes. European Journal of Medicinal Chemistry, 123, 487-507. https://doi.org/10.1016/j.ejmech.2016.07.057

Dekić, M., Kolašinac, R., Radulović, N., Šmit, B., Amić, D., Molčanov, K., Marković, Z. (2017). Synthesis and theoretical investigation of some new 4-substituted flavylium salts. Food Chemistry, 229(April), 688-694. https://doi.org/10.1016/j.foodchem.2017.02.13 9

Gavara, R., Gago, S., Jordão, N., \& Pina, F. (2014). 4'-carboxy-7-hydroxyflavylium. A multistate system involving twelve species reversibly interconverted by $\mathrm{pH}$ and light stimuli. The Journal of Physical Chemistry. A, 118(26), 4723-4731. Retrieved from http://www.ncbi.nlm.nih.gov/pubmed/248926 92

Kumar, D., Sharma, P., Singh, H., Nepali, K., Gupta, G. K., Jain, S. K., \& Ntie-Kang, F. (2017). The value of pyrans as anticancer scaffolds in medicinal chemistry. RSC Advances, 7(59), 36977-36999.

https://doi.org/10.1039/c7ra05441f

Mahadevan, D., Periandy, S., \& Ramalingam, S. (2011). Vibrational spectroscopy (FTIR and FTRaman) investigation using ab initio (HF) 
and DFT (B3LYP) calculations on the structure of 3-Bromo phenol. Spectrochimica Acta - Part A: Molecular and Biomolecular Spectroscopy, 78(2), 575-581. https://doi.org/10.1016/j.saa.2010.11.025

Orlikova, B., Tasdemir, D., Golais, F., Dicato, M., \& Diederich, M. (2011). Dietary chalcones with chemopreventive and chemotherapeutic potential. Genes and Nutrition, 6(2), 125-147. https://doi.org/10.1007/s12263-011-0210-5

Pavia, D.L., Lampman, G.M., Kriz, G.S. and Vyvyan, J. A. (2014). Introduction to Spectroscopy $5^{\text {th }}$ Ed. Cengage Learning;

Pratap, R., \& Ram, V. J. (2014). Natural and Synthetic Chromenes, Fused Chromenes, and Versatility of Dihydrobenzo[ $h$ ]chromenes in Organic Synthesis. Chemical Reviews, 114(20), 10476-10526. https://doi.org/10.1021/cr500075s

Rammohan, A., Reddy, J. S., Sravya, G., Rao, C. N., \& Zyryanov, G. V. (2020). Chalcone synthesis, properties and medicinal applications: a review. Environmental Chemistry Letters. https://doi.org/10.1007/s10311-019-00959-w

RJ, K. (2011). An efficient fluorescent polymer sensing material for detection of traces of benzo [a] pyrene in environmental samples. Environmental Chemistry Letters, 9, 389-395.

Robert M. Silverstein, F. X. W. (2005). Spectrometric Identification of Organic Compounds $7^{\text {th }} \mathrm{Ed}$.

Rosaleen J. Anderson, David J. Bendell, P. W. G. (2004). Organic Spectroscopic Analysis.

Sudha, S., Sundaraganesan, N., Vanchinathan, K., Muthu, K., \& Meenakshisundaram, S. (2012). Spectroscopic (FTIR, FT-Raman, NMR and $\mathrm{UV})$ and molecular structure investigations of 1,5-diphenylpenta-1,4-dien-3-one: A combined experimental and theoretical study. Journal of Molecular Structure, 1030, 191-
203.

https://doi.org/10.1016/j.molstruc.2012.04.030

Tomasch, M., Schwed, J. S., Weizel, L., \& Stark, H. (2012). Novel chalcone-based fluorescent human histamine $\mathrm{H} 3$ receptor ligands as pharmacological tools. Frontiers in SYSTEMS NEUROSCIENCE, $6, \quad 1-16$. https://doi.org/10.3389/fnsys.2012.00014

Tran, T.-D., Nguyen, T.-C.-V., Nguyen, N.-S., Nguyen, D.-M., Nguyen, T.-T.-H., Le, M.-T., \& Thai, K.-M. (2016). Synthesis of Novel Chalcones as Acetylcholinesterase Inhibitors. Applied Sciences, 6(7), 198. https://doi.org/10.3390/app6070198

Watanabe, H., Saji, H., \& Ono, M. (2018). Novel Fluorescence Probes based on the Chalcone Scaffold for In vitro Staining of \&\#x003B2;Amyloid Plaques. Bioorganic \& Medicinal Chemistry Letters. https://doi.org/10.1016/j.bmcl.2018.08.009

Yadav, N., Dixit, S. K., Bhattacharya, A., Mishra, L. C., Sharma, M., Awasthi, S. K., \& Bhasin, V. K. (2012). Antimalarial Activity of Newly Synthesized Chalcone Derivatives In Vitro. Chemical Biology and Drug Design, 80(2), 340-347. https://doi.org/10.1111/j.17470285.2012.01383.x

Zhou, B., Jiang, P., Lu, J., \& Xing, C. (2016). Characterization of the Fluorescence Properties of 4-Dialkylaminochalcones and Investigation of the Cytotoxic Mechanism of Chalcones. Arch. Pharm. Chem. Life Sci, 349, 1-14. https://doi.org/10.1002/ardp.201500434

Zhuang, C., Zhang, W., Sheng, C., Zhang, W., Xing, C., \& Miao, Z. (2017). Chalcone: A Privileged Structure in Medicinal Chemistry. Chemical Reviews, 117(12), 7762-7810. https://doi.org/10.1021/acs.chemrev.7b00020 